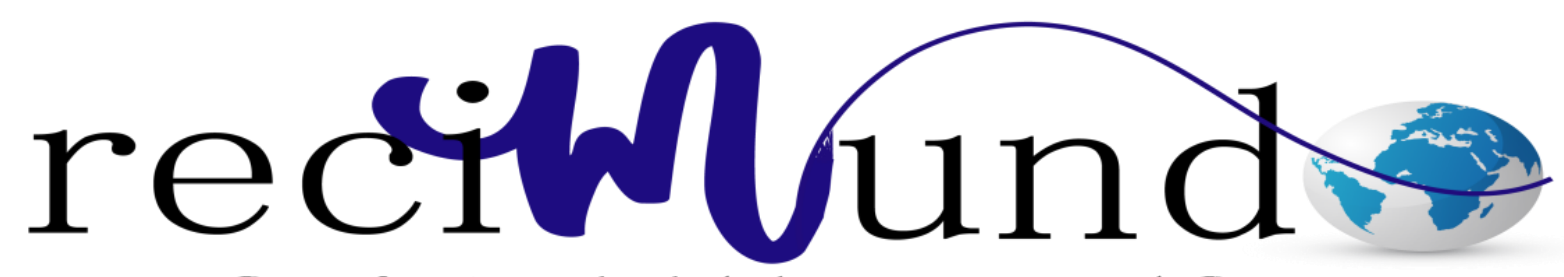

Revista Cientifica Mundo de la Investigación y el Conocimiento

Javier David Lara Icaza ${ }^{\text {a }}$

Cepas de Candida albicans en pacientes con diabetes mellitus

Strains of Candida albicans in patients with diabetes mellitus

Revista Científica Mundo de la Investigación y el Conocimiento. Vol. 3 núm.1, enero, ISSN: 2588-073X, 2019, pp. 1306-1339

DOI: $10.26820 /$ recimundo/3.(1).enero.2019.1306-1339

URL: http://www.recimundo.com/index.php/es/article/view/418

Código UNESCO: Estomatología 3213.13

Tipo de Investigación: Artículo de Revisión

Editorial Saberes del Conocimiento

Recibido: 20/11/2018 Aceptado: 05/01/2019 Publicado: 31/01/2019

Correspondencia: director@ recimundo.com

a. Magister en Microbiología mención Biomédica; Licenciado en Laboratorio Clínico; Tecnólogo Medico en Laboratorio Clínico. 


\section{Cepas de Candida albicans en pacientes con diabetes mellitus}

Vol. 3, núm. 1., (2019)

Javier David Lara Icaza

\section{RESUMEN}

Un pequeño número de hongos son capaces de causar enfermedades en el hombre. Es de gran importancia, conocer y priorizar la investigación sobre la resistencia farmacológica a las que se están presentando en la infección oportunista, es el caso de la Cándida albicans, son en pacientes que se encuentran inmunodeprimidos por enfermedades degenerativas como es la diabetes. Los diabéticos por la cantidad de azúcar en la sangre no mantienen el equilibrio simbiótico con esta clase de hongo, tornándose oportunista al aprovechar la debilidad corporal y al incurrir en una reproducción exponencial de sus colonias infectivas, dañando principalmente las mucosas y los tejidos del individuo. Se ha realizado una selección de textos y explicaciones concernientes no solo a describir y definir la enfermedad de la diabetes sino a comprender perfectamente el comportamiento del hongo según los estudios disponibles para conocer de qué manera se limita la fitoterapia conocida para el tratamiento cuando se trata de pacientes diagnosticados diabéticos. La infecciones oportunistas por Cándida albicans en pacientes diabéticos están ocasionando una tasa alta de incidencia en las infecciones candidiásica y por la cultura ecuatoriana a la automedicación estamos promoviendo. Entre las zonas corporales, a las cuales se ven expuesto, los pacientes diabéticos a sufrir de una infección por candidiasis, va a estar mediada por el buen control de la diabetes mellitus. Siendo esta una enfermedad de fondo, un factor intrínseco degenerativo, que no solo debilita al sistema inmune, si no que deshidrata y quebranta la piel, cambia el ph corporal, produce desnutrición por la mala asimilación de los nutrientes, produce estados inflamatorios en los órganos, obstaculiza la formación y el tránsito de las células inmunocompetentes, lo que permite a la Cándida spp, como parte de la microflora, se transformarse en oportunista y causar una infección en el organismo.

Palabras Claves: Cándida albicans; diabetes mellitus; recidiva; antifúngicos; microflora; antifungitest. 


\title{
Cepas de Candida albicans en pacientes con diabetes mellitus
}

Vol. 3, núm. 1., (2019)

Javier David Lara Icaza

\begin{abstract}
A small number of fungi are capable of causing diseases in man. It is of great importance to know and prioritize research on drug resistance to those that are occurring in opportunistic infections, as in the case of candida albicans, in patients who are immunocompromised due to degenerative diseases such as diabetes. Diabetics by the amount of sugar in the blood do not maintain the symbiotic balance with this kind of fungus, becoming opportunistic to take advantage of the body weakness and incur an exponential reproduction of their infective colonies, mainly damaging the mucous membranes and tissues of the individual. We have made a selection of texts and explanations concerning not only to describe and define the disease of diabetes but also to fully understand the behavior of the fungus according to the available studies to know how the phytotherapy known for treatment is limited when it comes to diabetic patients diagnosed. The opportunistic infections by candida albicans in diabetic patients are causing a high rate of incidence in candidiasis infections and by the Ecuadorian culture to self-medication we are promoting. Among the body areas, to which they are exposed, diabetic patients to suffer from an infection by candidiasis, will be mediated by the good control of diabetes mellitus. Being this an underlying disease, an intrinsic degenerative factor, which not only weakens the immune system, but also dehydrates and breaks the skin, changes body $\mathrm{pH}$, produces malnutrition due to poor assimilation of nutrients, produces inflammatory states in organs, hinders the formation and transit of immunocompetent cells, which allows the candida spp, as part of the microflora, to become opportunistic and cause an infection in the organism.
\end{abstract}

Key Words: Cándida albicans; diabetes mellitus; relapse; antifungals; microflora; antifungitest. 


\section{Cepas de Candida albicans en pacientes con diabetes mellitus}

Vol. 3, núm. 1., (2019)

Javier David Lara Icaza

\section{Introducción.}

Un pequeño número de hongos son capaces de causar enfermedades en el hombre. Las invasiones al tejido del hospedador son accidentales, ya que su hábitat normal es el suelo. Pero dentro de las excepciones están los hongos comensales partes de la microflora humana que conviven con nosotros y hasta cierto punto son necesarios como un mecanismo de defensa externo. El problema es cuando esa delgada línea de complicidad se rompe para dar origen a la patología.

La frecuencia de infecciones causadas por cándida spp., microorganismo comensal de alguna manera habitual en el organismo, ha aumentado en forma significativa en las últimas décadas, convirtiéndola actualmente en la infección micótica más común y predecible. Se ha referido en las unidades de uci en E.U.A. Un aumento de 4 veces las tasas de fungemía nosocomial entre 1980 y 1990, representando alrededor del $10 \%$ de todas las infecciones del torrente sanguíneo durante la década de los 90. (Oddo, a. 2008)

Se piensa que el hongo ha mutado, presentado resistencia a la farmacología tradicional revelándose, como un patógeno agresivo para los diabéticos. La velocidad que los hongos modifican su genoma, creando una variedad pleomórficas, muy diversa dotándolos de herramientas complejas, las cuales son el resultado a las exposiciones a medios hostiles, sea este natural o inducido. En base a esta capacidad de perpetuar la especie micológica, las nuevas colonias son capaces de protegerse contra la farmacología rutinaria, esto promueve a una investigación continua de nuevos mecanismo terapéuticos más eficaces en eliminar o controlar dichos patógenos. Pero no solo son los hongos, también el hombre como sociedad ha ayudado a facilitar a los cambios con la exposición a los tratamientos médicos, sin seguir las dosis 


\section{Cepas de Candida albicans en pacientes con diabetes mellitus}

Vol. 3, núm. 1., (2019)

Javier David Lara Icaza

correctas, suspenden la medicación por descuido o la farmacodependencia arbitraria sin ser prescrita por un profesional de la salud.

La resistencia micológica va en un creciente aumento. En los país en vías de desarrollo se han evidenciado estudios de resistencia al fluconazol, un azolítico que la cándida albicans presenta poca sensibilidad, hasta en el 9,5\% en paises de África como Nigeria (Ca, 2008). En Colombia, obtuvieron de muestras de orofaríngea, 56 pacientes con candidiasis oral pseudomembranosa con infección por VIH/Sida, encontrando resistencia al fluconazol del 20,8\% para cándida sp. Y 6,3\% con patrón sensible dosis dependiente (sdd). (Gutiérrez C., 2007)

No menos importante es la frecuencia de cándida spp. Como causante de otras infecciones comunes como la vulvovaginitis, que se reportan con resistencia a azoles (Alburquerque, 2009) y complicaciones infecciosas en huéspedes inmunodeprimidos que reciben terapias inmunosupresoras o terapia biológica que son motivo de preocupación por el cambio en la epidemiología de este tipo de infecciones.

Además, la idiosincrasia del medio social ecuatoriano actúa de coautores de la evolución micológica, motivando a los médicos administrar, dosis por más tiempo y en mayores proporciones, no cumpliéndose esta prescripción médica en los pacientes diabético, favoreciendo la evolución de la cándida y el recrudecimiento de las candidiasis.

Los diabéticos por la cantidad de azúcar en la sangre que, normalmente no puede ser absorbida y metabolizada por las células, resultado de la incapacidad del páncreas en producir insulina, debilita al organismo, deprimiendo la producción de glóbulos blancos, los cuales, no mantienen el equilibrio simbiótico con esta clase de hongo, tornándose oportunista al aprovechar 


\section{Cepas de Candida albicans en pacientes con diabetes mellitus}

Vol. 3, núm. 1., (2019)

Javier David Lara Icaza

la debilidad corporal y al incurrir en una reproducción exponencial de sus colonias infectivas, dañando principalmente las mucosas y los tejidos del individuo.

A pesar que los antimicóticos son efectivos para combatir la candidiasis, no lo son del todo para los diabéticos, su condición inmunodeprimida lo vuelven vulnerables a las micosis, asimismo esta patología degenerativa de fondo, trastorna la conducta de quien la padece. Como resultado de esto hay un bajón anímico, aflorando de manera recidivante las micosis candidiásicas, además la idiosincrasia del medio social y cultural del guayaquileño, hace que la solución se aplace al no acudir tempranamente al médico y con esto da paso a la automedicación como herramienta de fácil adquisición y rápida para sus males.

La automedicación o el aplazamiento de la terapia antimicótica temprana brindarán al microorganismo, el tiempo necesario para crear algún tipo de defensa contra los antifúngicos, transformando y expresando potenciales mecanismos de resistencia a los fármacos. Esto ha provocado un desafío a los investigadores en el campo farmacológico, una lucha diaria asumimos los profesionales de la salud y más los microbiólogos, epidemiólogos y clínicos, en tratar de evitar que los pacientes consuman medicamentos fuera del esquema terapéutico ideal o en su efecto que, terminen el esquema farmacológico sin interrumpir la dosis necesarias, tratando de disminuir la resistencia micológica.

Es de gran importancia, el conocer y priorizar la investigación sobre la resistencia farmacológica a las que se están presentando en las infección oportunista, es el caso de la cándida albicans, son en pacientes que se encuentran inmunodeprimidos por enfermedades degenerativas como es la diabetes. Las mayorías de los hongos se transforman en patógenos para 


\section{Cepas de Candida albicans en pacientes con diabetes mellitus}

Vol. 3, núm. 1., (2019)

Javier David Lara Icaza

quienes padecen de esta enfermedad de fondo, pero la cándida como parte de flora es la primera que coloniza de manera abrupta cuando las condiciones ambientales acompañan a la infección.

Más de 150 especies de cándida spp. Existen, pero solo 10 son descritas como patógenos e importantes para la investigación en el ser humano. Un gran número de investigaciones sugieren que la cándida albicans es la especie más común que se presenta en la mucosa, piel, uñas y en las cavidades corporales por tal motivo son frecuente las micosis oportunistas. Además, la tasa alta de colonización por hongos y patologías se presenta en pacientes con un pobre control de la glicemia.

Cabe también recalcar la importancia de conocer las posibles amenazas de la diversidad micológica, en lo que refiere a resistencia farmacológica, porque demanda un peligro potencial al mundo mientras más fuerte y preparado este nuestro agresor difícilmente podremos vencerlo, lo que nos conllevaría a usar dosis muy altas causando patologías adversas a la enfermedad inicial, complicando la salud del paciente.

El propósito de este estudio es identificar teóricamente la razón por la que se llega a sospechar que las cepas de cándida albicans desarrollaron algún tipo de resistencia a la farmacología empleada y por condiciones inmunodeprimidas debemos inmediatamente encontrar el fármaco más idóneo para los pacientes diabéticos.

\section{Metodología.}

La presente tesis será una investigación descriptiva correlacional teórica y bibliográfica que lleven al proceso del análisis micológico y clínico en relación a la terapia farmacológica 


\section{Cepas de Candida albicans en pacientes con diabetes mellitus}

Vol. 3, núm. 1., (2019)

Javier David Lara Icaza

empleada en el agente patógeno micótico causantes de las infecciones con cepas cándida albicans.

Para el cumplimiento de presente se realizaron los siguientes métodos de investigación:

- Analítico-sintético: porque manejamos juicios considerando cada una de las causas, las cuales fueron clasificadas, para conocer su principal origen y llegar a una conclusión.

- Inductivo-deductivo: para estudiar las diferentes causas particulares a una causa generalizada y realizar análisis partiendo de lo general a lo particular, aplicando una lógica para entender y explicar las causantes del de la resistencia a los antimicóticos. Llevándonos al método hipotético-deductivo para exponer todo el marco teórico que acompaña la comprensión del caso planteado

- Se ha realizado una selección de textos y explicaciones concernientes no solo a describir y definir la enfermedad de la diabetes sino a comprender perfectamente el comportamiento del hongo según los estudios disponibles para conocer de qué manera se limita la fitoterapia conocida para el tratamiento cuando se trata de pacientes diagnosticados diabéticos.

\section{Resultados.}

- Candida albicans: taxonomía; morfogénesis y recuperación in vitro.

- Candida albicans: taxonomía.

- Taxonomía según facultad de odontología de Venezuela. (Duarte, 2011) 


\section{Cepas de Candida albicans en pacientes con diabetes mellitus}

Vol. 3, núm. 1., (2019)

Javier David Lara Icaza

- Reino: hongo.

- División: deuteromycota clase: blastomycetes familia: cryptococcaceae género: cándida.

- Especies: albicans (la más frecuente y virulenta).

- Taxonomía según la universidad de valencia.- España. (La Foret, 2010)

- Reino: fungi.

- Phylum: ascomycota subphylum: ascomycotina clase: ascomicetes.

- Orden: saccharomycetales familia: saccharomycetaceae género: cándida.

Este hongo comprende más de 150 géneros, cuya principal característica es la ausencia de forma sexual, con excepción de algunas especies micóticas. Se clasifican como levaduras con un predominante desarrollo unicelular. Solo una docena de especies tienen la facultad de adaptarse a una temperatura de $37^{\circ} \mathrm{c}$. Y pueden ser esporádicamente dañinas para el hombre, estas son entre otras:

Candida albicans, cándida tropicalis, cándida kefyr (pseudotropicalis), cándida krusei, cándida guillermondi, cándida parakrusei, cándida zeylanvides, cándida stellatoidea y cándida brumptii. (Pontón, 2007)

Regulación de morfogénesis de la cándida albicans por señales del medio ambiente

El proceso de inducción de las hifas en cándida albicans, consta de tres fases. En la primera: las señales externas son percibidas por receptores específicos localizados en la superficie celular. La segunda: se activan las señales de transducción intracelular, y en la tercera 


\section{Cepas de Candida albicans en pacientes con diabetes mellitus}

Vol. 3, núm. 1., (2019)

Javier David Lara Icaza

fase: se producen los componentes reguladores estructurales necesarios para la formación de la hifa. (La Foret, 2010)

Para un eficiente proceso morfogenético se requiere la presencia o ausencia de elementos reguladores o represores. Se conocen al menos tres factores que actúan positivamente en la formación de hifas, estos son:

- $\quad$ Temperatura a $37^{\circ} \mathrm{c}$.

- PH neutro y.

- Crecimiento en medio líquido a baja densidad (<0.1-0.5 do600).

Previo ayuno metabólico en las condiciones anteriores de temperatura y de $\mathrm{pH}$. Han sido descritas numerosas sustancias que funcionan como inductores positivos del crecimiento en forma de hifa. El inductor más efectivo y fisiológico es el suero (5-20\%) capaz de promover una elevada producción de tubos germinativos en cándida albicans. (La Foret, 2010)

Tipos de cándida: especies

La cándida tiene más 150 especies, pero las que pueden afectar al hombre porque soportan la temperatura corporal son:

Candida albicans; cándida glabrata; cándida guilliermondii; cándida krusei; cándida parapsilosis; cándida tropicalis; cándida dubliniensis (Washington, 2008)

Y son las principales que se estudian en los laboratorios, por ser las causantes de este tipo de infecciones "candidiásicas". Esta patología en el ser humano se da por el estado 


\section{Cepas de Candida albicans en pacientes con diabetes mellitus}

Vol. 3, núm. 1., (2019)

Javier David Lara Icaza

inmunodeprimido a consecuencia de la diabetes no controlada. En el estudio nos enfocaremos exclusivamente a la cándida albicans que es la más común de esta infección.

\section{Candida in vitro}

Porque recuperamos el germen cándida

Recuperamos estén germen para recrear "in vitro" la colonia de cándida y poder someterla a la prueba de sensibilidad a los fármacos. Luego de determinar el género cándida, se la inoculará en medios cromogénicos y después de la siembra pertinente, sabremos a que especie pertenece. (Jaimez, 2008) obteniendo resultados confiables de la potencial especie y género que está causando la infección a los pacientes diabéticos y qué tipo de resistencia presentan las cepas aisladas. Beneficiando al pacientes diabético que está atravesado un cuadro de candidiasis recidivante.

Medios de cultivo tradicionales para cándidas spp. Y levaduras

Los medios más utilizados en el cultivo de levaduras son: agar saboread glucosa (ags), habitualmente con la modificación de emmons, con cloranfenicol y con/sin actidiona. Sin embargo la elección y el número de medios a utilizar están condicionados por el costo, la disponibilidad y las preferencias personales, pero siempre se deben incluir medios con antibacterianos y sin ellos' (Sánchez, 2009) la incorporación inhibidor de muchos hongos considerados contaminantes, ayuda especialmente en las micosis de la piel, para esto en el mercado hay diferentes medios de cultivo:

- Agar sabouraud + glucosa modificado por Emmons. 


\section{Cepas de Candida albicans en pacientes con diabetes mellitus}

Vol. 3, núm. 1., (2019)

Javier David Lara Icaza

- (Rodero, 2006).

- Bd biggy agar (agar biggy bd) (Washington, 2008).

- Agar sabouraud con cicloheximida y cloranfenicol (Duarte A. E., 2011) (Rodero, 2006).

- Medios cromogénicos para levaduras (Washington, 2008) (Duarte A. 2011).

- Agar harina de maíz (Duarte A. 2011) (Manzano, 2011).

- Agar lactrimel (Washington, 2008).

Característica de la colonia de cándida

El aspecto microscópico de las especies de cándida es igual a todas las levaduras. Son gram positivas, pero en algunas ocasiones, las formas de las blastosporas pueden variar de ovoide a elongada o esférica. Microscópicamente, cándida albicans presenta dimorfismo, el cual es una transformación de la forma ovoide de las blastosporas (levaduras) gemantes a hifas. Por su parte, duarte sostiene que el material blanco que crece en los medios de cultivo consiste desde el punto de vista microscópico, en pseudomicelio actualmente llamados filamentos de cándida albicans. (Duarte A., 2011)

Como explica duarte, este material blanco se presenta bajo condiciones de cultivo semianaeróbico o facultativo y está formado por células elongada que se mantienen unidas entre sí, como cadena. Las blastoconidias o blastosporas que están agrupadas en montones a lo largo del pseudomicelio, en los sitios en que los extremos finales de las células pseudomiceliales se empalman con otras. En contraste con otras especies de cándida. La cándida albicans tiene una marcada tendencia a formar esporas grandes de pared gruesa, denominadas clamidosporas. (Tortora, 2007)

Cuando se cultivan en un medio especial como agar harina de maíz; la clamidospora tiene un diámetro de 7 a 8 micras y casi siempre se origina en el extremo del pseudomicelio. Es una 


\section{Cepas de Candida albicans en pacientes con diabetes mellitus}

Vol. 3, núm. 1., (2019)

Javier David Lara Icaza

importante característica morfológica en la identificación de cándida albicans. Asimismo, tiene la capacidad para producir tubos germinales (filamentación en suero) cuando las colonias son inoculadas en $0,5 \mathrm{ml}$. De suero a temperatura de $37^{\circ} \mathrm{c}$. Observándose los resultados después de 2 o 3 horas. (Duarte A., 2011)

Macroscópicamente la colonia se presenta según el medio donde creció. El agar sabouraud; las colonias de levaduras suelen ser completas, ligeramente abombadas o planas, de consistencia mantecosa, lisas o rugosas, con olor dulzón agradable, de color blanco, volviéndose más pastosas a medida que envejecen. (Forbes, 2009)

En cambio, en agar bd biggy; después de la incubación, los aspecto de los organismos cambian, las colonias de cándida albicans, son de color rojo amarronado a negro, sin difusión de pigmento en el medio sin brillo; cándida tropicalis, colonias de color marrón oscuro con centros negros y brillo, oscurecimiento difuso del medio circundante (a menudo sólo después de 72 h de incubación). Candida krusei, colonias grandes, planas, de color marrón rojizo, con parte superior negra brillante, borde marrón y halos amarillentos. Candida pseudotropicalis, colonias grandes, de color marrón rojizo y planas con borde micelial. Candida glabrata, colonias de color marrón pálido a claro. (Manzano, 2011)

\section{Filamentación en suero}

Como unas de las pruebas del tipo confirmatorias para la especie albicans, es la presencia del tubo germinal, el mismo que se define como una extensión filamentosa de una célula levaduriforme que mide alrededor de la mitad del ancho y tres a cuatro veces el largo de la celular. (Rueda, 2008) el tubo germinal de cándida albicans ha sido descrito como un tubo sin 


\section{Cepas de Candida albicans en pacientes con diabetes mellitus}

Vol. 3, núm. 1., (2019)

Javier David Lara Icaza

constricción en el punto de origen y tienen una apariencia similar a "espejo de mano". (Duarte A., 2011)

Este puede formarse al inocular células de cándida albicans en suero humano (inclusive si el suero ha sido congelado y almacenado), así como en suero de diversos animales como perro, bovino, conejo, cochino de guinea y caballo. En cambio, este no se forma en suero caliente coagulado (Cárdenas, 2008)

La formación de tubos germinales en suero está afectada directamente por la concentración celular en el inoculo, ya que la proporción de células capaces de formar filamentos, disminuye progresivamente al aumentar la concentración celular por encima de 107 células por ml. De igual forma, el científico Mackenzie, en el año 1962 demostró mediante su investigación "serum tube identification of cándida albicans" que el rango de temperatura en el cual se forman los tubos germinales oscila entre $31^{\circ} \mathrm{c} \mathrm{y} 41^{\circ} \mathrm{c}$.

Pruebas de identificación micológica a través de sustratos bioquímicos en colonias in vitro

En la actualidad se cuenta con diversos métodos para identificar las especies de cándida, los cuales varían en tiempo, especificidad, sensibilidad, costos, entre otros. De esta manera, cada laboratorio puede adoptar los más acordes a su capacidad y disponibilidad. Las técnicas de identificación más comúnmente utilizadas comprenden: 1. Estudio morfológico; 2. Pruebas rápidas; 3. Estudio fisiológico y bioquímico; 4. Métodos automatizados; 5. Medios diferenciales; 6. Métodos inmunológicos; 7. Biología molecular. Las tres primeras técnicas comprenden diversos ensayos, los cuales son referidos por lo general como pruebas convencionales rápidas de identificación. (Ilarte, 2009) 


\section{Cepas de Candida albicans en pacientes con diabetes mellitus}

Vol. 3, núm. 1., (2019)

Javier David Lara Icaza

Entre las pruebas fisiológicas y de asimilación del carbono, comprenden una serie de ensayos de asimilación (auxonograma-degradación aeróbica) y fermentación (zimogramadegradación anaeróbica) de carbohidratos para la identificación de levaduras. En el auxanograma, la asimilación del azúcar se detecta por el crecimiento visible y cambio del indicador de color en el medio de cultivo, mientras que en el zimograma, su producto se detecta a través de la producción de gas (hidrógeno y anhídrido carbónico). (Ilarte, 2009)

Se seleccionan con mayor fiabilidad las pruebas de auxonogramas, por causa de la existencia de ciertos carbohidratos que forman parte de la estructura celular de estos microorganismos, los cuales podrían revelar resultados falsos positivos en la prueba de fermentación de determinadas sustancias carbonadas. El auxonograma se trata de un método muy poco utilizado actualmente, debido fundamentalmente a lo laborioso del mismo, por lo que se han comercializado algunos que facilitan la identificación de las levaduras. (Lobaina, 2010)

\section{Candidiasis y resistencia antimicótica}

\section{Candidiasis o candidosis}

Es una infección micótica causadas por levaduras, que son organismos unicelulares del género cándida spp, con manifestaciones clínicas extremadamente variables de evolución y que pueden variar desde aguda, subaguda, crónica o esporádica (cárdenas, 2008), en las cuales el hongo puede causar lesiones cutáneas, mucocutáneas, profundas y sistémicas. 


\section{Cepas de Candida albicans en pacientes con diabetes mellitus}

Vol. 3, núm. 1., (2019)

Javier David Lara Icaza

Agentes etiológicos:

El principal agente etiológico que causa la candidiasis en los organismos humanos, es al hongo cándida albicans, pero pueden estar implicadas otras especies de cándida, como las: cándida dubliniensis; cándida glabrata; cándida famata; cándida krusei; cándida lusitaniae; cándida parapsilosis; cándida tropicalis: etc. (Forbes, 2009) levaduras de otros géneros distintos de cándida como saccharomyces, pichia, rhodotorula pueden dar cuadros clínicos similares a la candidiasis.

Formas clínicas de la candidiasis (Núñez, 2011)

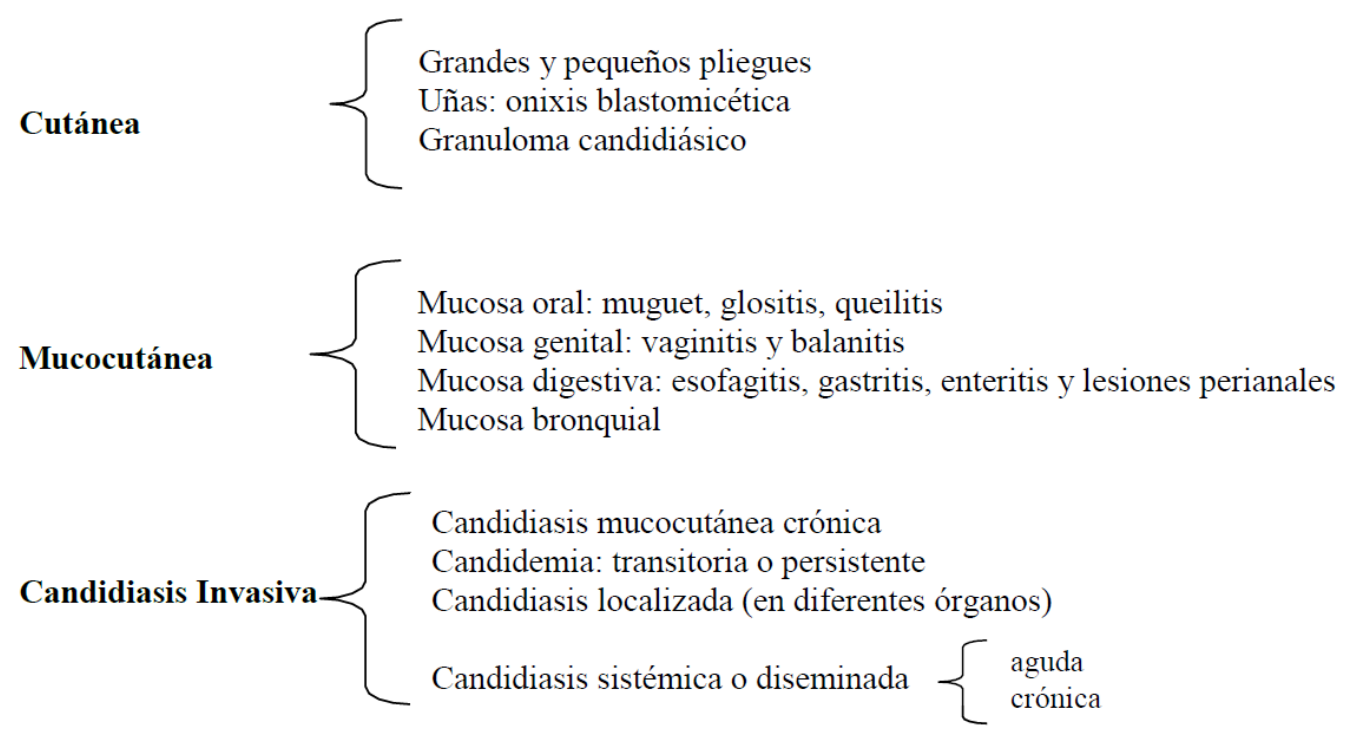

Candidiasis Invasiva

Alérgica

Terapia farmacológica 


\section{Cepas de Candida albicans en pacientes con diabetes mellitus}

Vol. 3, núm. 1., (2019)

Javier David Lara Icaza

\section{Farmacología e importancia en la sociedad}

La farmacología como ciencia, nos ha ayudados a conocer la actividad de los fármacos en los organismos vivos. Dotando a los médicos de herramientas eficaces para vencer a los microrganismo que afectan a una población determinada. Asimismo ella estudia el origen, las acciones y las propiedades de las sustancias, sean estas naturales o químicamente sintéticas.

Se considera como el estudio de los fármacos, a los cuales se les atribuyen efectos beneficiosos o tóxicos para el individuo, con posibles aplicaciones clínicas, cuando las sustancias son utilizadas y empleadas en el diagnóstico, prevención, tratamiento y alivio de síntomas de una patología. También se puede hablar de la farmacología, como el estudio unificado de las propiedades de las sustancias químicas, de los organismos vivientes y de todos los aspectos de sus interacciones en la absorción, asimilación y eliminación de los componentes químicos, orientado hacia el tratamiento, diagnóstico y prevención de las enfermedades.

Desde la antigüedad las escrituras dan explicación de este tipo de conocimiento médico, las más antiguas se encontraron en mesopotamia y están constituidas por tablillas de arcilla grabadas en escritura cuneiforme; allí se describe el uso de plantas como la casia, el tomillo y la adormidera. En el código de Hammurabi (1700 ac) (Morón, 2012) más tarde en la era de los griegos Hipócrates se lo considera, quien liberó a la medicina de la mística, basándola en una terapéutica racional, entendiendo a las enfermedades como una acción, al que el organismo humano perdía su salud y administrando las acciones y propiedades curativa de ciertas plantas podía devolver la salud. 


\section{Cepas de Candida albicans en pacientes con diabetes mellitus}

Vol. 3, núm. 1., (2019)

Javier David Lara Icaza

En la sociedad moderna. La farmacología ha marcado las pautas para sobrellevar a las enfermedades, frenando parcial o total a las patologías; que hace dos siglos atrás, hubiera desbastados con la mitad de la población existente. Basándonos en los compuestos de las plantas y de sustancias aisladas en el laboratorio, hemos podido eliminar y controlar algunos a los microrganismos, que en algún tiempo colonizaron y atacaron a organismos vivientes humanos sin posibilidades de sobrevivencia.

En la actualidad el pronóstico de vida, de los seres humanos, se ha duplicado en el último siglo. Esto se debe a una renovación y estructuración de la farmacología, administrando oportuna y dirigidamente la medicación, acortando los cuadros de incubación, trasmisión y multiplicación de los agentes microbianos.

Hoy por hoy, hay un peligro inminente que está surgiendo, y va ligado a la cultura de los ciudadanos. No proviene directamente de los microorganismos, sino de un efecto colateral y es la automedicación. Si bien la humanidad se ha beneficiado de la sustancias químicas también han minimizados la importancia y el peligro del uso excesivo.

La automedicación empírica y exagerada en el uso de los fármacos, han brindado a los hongos, bacterias y virus, las posibilidades, que por el tiempo a la exposición a los mismos, sin el efecto continuo del antibiótico. Los gérmenes estén desarrollando mecanismos de defensa o también llamados factores de resistencia a los fármacos que algún momento los eliminaron. Sin olvidar que estos repercute que las dosis administradas en lo posterior sean mayores, acercándonos a una dosis letal para el organismo.

Clasificación de los antifúngico (Gómez, 2010). 


\section{Cepas de Candida albicans en pacientes con diabetes mellitus}

Vol. 3, núm. 1., (2019)

Javier David Lara Icaza

Antibióticos

- Polienos.

- Sistémicos: anfotericina b tópicos: nistatina y natamicina no polienos: griseofulvina.

Azoles

- Imidazoloes; miconazol.

- Triazoles: ketoconazol; itraconazol; fluconazol; voriconazol; posaconazol tópicos:

bifonazol; butoconazol; cotrimazol; econazol; fenticonazol; flutrimazol; omoconazol; sulconazol; tioconazol; terconazol.

Pirimidinas fluoradas

- Flucitosina

Equinocandinas

- Caspofungina; micafungina; anidulafungina

Alilaminas

- Terbinafinas; naftifina

Otros:

Yoduro potásico; ciclopirox; tolnaftato 


\section{Cepas de Candida albicans en pacientes con diabetes mellitus}

Vol. 3, núm. 1., (2019)

Javier David Lara Icaza

\begin{tabular}{|c|c|c|}
\hline ANTIFÚNGICOS & DIANA & MECANISMO DEACCIÓN \\
\hline Griseofulvina & Microtúbulos & Interfiere con el ensamblaje delosmicrotubulos. \\
\hline Flucitosina & ARN & Inhibicón dela síntesis proteica. \\
\hline $\begin{array}{c}\text { Antibióticos } \\
\text { Macrólidos poliénicos } \\
\text { (nistatina, anfotericina B) }\end{array}$ & Ergosterol & $\begin{array}{c}\text { Formación de poroshidrofilicos en la membrana } \\
\text { plasmática. }\end{array}$ \\
\hline $\begin{array}{c}\text { Azoles } \\
\text { (ketoconazol, fluconazol, miconazol) }\end{array}$ & Citocromo P-450 & Alteración dela fluidezpermeabilidad celular. \\
\hline $\begin{array}{c}\text { Equinocandinas } \\
\text { Pneumocandinas }\end{array}$ & B-glucano sintasa & Alteración dela pared celular. \\
\hline Nikomicinasy Polioxinas & Quitina sintasas & Alteración dela pared celular. \\
\hline Pradimicinas & Manoproteínas & Alteración dela membrana plasmática. \\
\hline Sordarinas & Factor de elongación & Inhibenla síntesis proteica. \\
\hline
\end{tabular}

Fig. 1 órganos diana y mecanismo de acción de los antimicóticos

\section{Resistencia frente a los antimicóticos}

Desde la perspectiva clínica, la resistencia antibiótica puede definirse como la persistencia o progresión de una infección a pesar de la terapia adecuada. Los resultados clínicos del tratamiento dependen de la sensibilidad del patógeno a un cierto fármaco y a factores como la farmacocinética, interacciones farmacológicas, sistema inmunológico y cumplimiento por parte del paciente. La resistencia puede determinarse como la concentración inhibitoria mínima que restringe el crecimiento de hongos in vitro. (Cortés, 2011)

Sin embargo, este parámetro en oportunidades sólo pronostica el resultado clínico. Las diferencias en las sensibilidades a los antimicóticos entre patógenos, poblaciones y especies reflejan distintas escalas de tiempo de evolución. La resistencia antibiótica puede ser primaria, cuando el hongo es resistente a una droga antes de su exposición, o secundaria, cuando un agente 


\section{Cepas de Candida albicans en pacientes con diabetes mellitus}

Vol. 3, núm. 1., (2019)

Javier David Lara Icaza

inicialmente sensible se hace resistente luego de la exposición. (Alburquerque \& et al, 2009) las especies de hongos presentan diferentes sensibilidades intrínsecas frente a distintos fármacos.

Muchas especies evidencian un amplio espectro de sensibilidades a determinada droga, con genotipos sensibles y resistentes. Poblaciones de especies podrían haberse adaptado a la droga luego de su exposición en cualquier momento de su historia. Según la magnitud de la cr, el fenotipo de resistencia puede persistir en ausencia del antimicótico. Los genotipos resistentes pueden ser transmitidos entre pacientes de un hospital y entre parejas sexuales.

En la escala evolutiva más contemporánea se encuentra el surgimiento de la resistencia, en una población de levaduras inicialmente sensibles que se adaptan a la droga en un paciente a largo del tratamiento. La resistencia a los polienos en general está asociada con la alteración de los lípidos de membrana, especialmente esteroles. La resistencia a los azoles está relativamente diseminada, especialmente en cándida albicans y cándida dublinienesis. (Gutiérrez, 2012) la resistencia a los azoles se encuentra asociada con la sobreexpresión de la enzima erg11 y mutaciones de otras enzimas que actúan en la síntesis del ergosterol, con eliminación activa de la droga por sobreexpresión de las bombas de flujo y disminución de la permeabilidad de la membrana por alteraciones en los esteroles. (Cowen, 2012)

\section{Mecanismo de alteración en resistencia de cándida albicans}

La cándida albicans, es un hongo que puede actuar como comensal o como patógeno oportunista en el hombre. Entre los factores que predisponen al padecimiento de candidiasis figuran los tratamientos inmunosupresores y quimioterápicos, la presencia de catéteres intravenosos, bajo peso al nacer, síndrome de inmunodeficiencia adquirida (sida), diabetes y 


\section{Cepas de Candida albicans en pacientes con diabetes mellitus}

Vol. 3, núm. 1., (2019)

Javier David Lara Icaza

drogadicción, entre otros. (Guery, 2009) dependiendo del estado inmunitario del paciente, dicho microorganismo puede producir una amplia gama de afecciones, desde candidiasis orofaríngea hasta infecciones diseminadas. (Paniagua, 2010)

Los pacientes desarrollan con frecuencia candidiasis. Coloniza las mucosas del organismo, causando enfermedad sintomática hasta en el $46 \%$ de ellos. El tratamiento con azoles, especialmente fluconazol, ha demostrado ser eficaz tanto in vitro como en estudios clínicos frente a cándida albicans, siendo considerado antimicótico de elección. (Torres, 2008). El fluconazol inhibe la síntesis del ergosterol mediante la unión a la enzima 14- $\alpha$-esterol desmetilasa dependiente del citocromo p-450, impidiendo con ello la conversión del lanosterol en ergosterol. La depleción del ergosterol celular, junto a la acumulación de ciertos compuestos intermedios en su síntesis, lleva en última instancia a una pérdida de la funcionalidad de la membrana plasmática, produciendo un efecto fungistático. (La Foret, 2010)

Pero en la actualidad, en los casos de pacientes con sida y diabetes están presentando episodios recurrentes de candidiasis, revelando el potencial de resistencia al fluconazol y a otros azoles. La prevalencia de resistencia a los azoles se ha estimado en un $21 \%$ a $32 \%$ en los pacientes sintomáticos, y hasta un $14 \%$ en los asintomáticos. (Rueda, 2008)

Entre los mecanismos moleculares de resistencia a los azoles hasta ahora descritos en cándida albicans figuran los siguientes:

- Alteraciones en la enzima diana (14- $\alpha$-esterol desmetilasa), derivadas tanto de la sobreexpresión de los genes que la codifican (ergg11) como de mutaciones concretos en éstos. Las mutaciones en erg11 originan sustituciones en aminoácidos, disminuyendo con 


\section{Cepas de Candida albicans en pacientes con diabetes mellitus}

Vol. 3, núm. 1., (2019)

Javier David Lara Icaza

ello la afinidad de la enzima por los azoles. (Rueda, 2008) (Tobar, 2011)

- Alteración en otras enzimas de la ruta biosintética del ergosterol (por ejemplo la ruta desaturasa [erg3]).(Rueda, 2008) (Tobar, 2011)

- Sistemas de bombeo activos del antifúngico al exterior de la célula, que impiden la acumulación intracelular del fármaco. (Rueda, 2008) (Tobar, 2011)

Genes de resistencia aislados en cándida albicans

Existen pocos genes descritos en cándida albicans hasta la fecha con un papel definido en la resistencia a azoles.

- Mdr1.

- Cdr1.

- Cdr2.

El mdr1: denominado inicialmente benr, fue aislado al conferir resistencia a los antibióticos benomilo y metotrexato en s. Cerevisiae (saccharomyces cerevisiae) cuando se encontraba presente en plásmidos episómicos multicopia de este organismo. Con posterioridad se demostró que su sobreproducción en s. Cerevisiae confería resistencia no sólo a estos antifúngicos sino a una amplia variedad de compuestos que no estaban relacionados estructuralmente como cicloheximida, benzotriazoles, nitroquinoleínas y otros. (Gutiérrez, 2012)

Mdr1 codifica una proteína, mdr1p, en la que se han sugerido dos dominios proteicos con seis regiones fuertemente hidrofóbicas (supuestamente transmembrana) cada una, así como su pertenencia a la familia de transportadores mfs (del inglés, major facilitators superfamily). Estas proteínas, actúan por un mecanismo dependiente de la existencia de un potencial de membrana. 


\section{Cepas de Candida albicans en pacientes con diabetes mellitus}

Vol. 3, núm. 1., (2019)

Javier David Lara Icaza

Mdr1p, es homólogo (57\% identidad, 77\% similitud) con una proteína similar de c. Maltosa que confiere resistencia a cicloheximida así como el producto de un gen de schizosaccharomyces pombe que confiere resistencia a amiloride denominado car1. La interrupción de este gen en c. Albicans ha demostrado su implicación en la virulencia. (La Foret, 2010)

Este aspecto apoya el hecho de que esta proteína, aunque no esencial, juega un papel importante en procesos fisiológicos normales en la célula fúngica. Se ha demostrado recientemente que la sobreproducción de mdrlconfiere resistencia a fluconazol y otros azoles. (Pappas, 2009) las cepas de cándida albicans seleccionadas en este gen son, igualmente, más sensibles a ciertos compuestos tóxicos aunque no a benomilo tampoco a los azoles.

Un segundo gen caracterizado es cdr1, codifica una proteína que, teniendo en cuenta su estructura primaria, pertenece a la superfamilia de transportadores de tipo abc (del inglés, atpbinding cassette), también implicados en la resistencia múltiple a drogas en este organismo. Estos transportadores, ampliamente difundidos en el mundo microbiano, actúan acoplando el sistema de transporte del sustrato a un proceso de hidrólisis de atp, que interacciona con una región definida de la proteína presente en un dominio citoplásmico. La sobreproducción de cdr1p confiere resistencia a múltiples drogas. (Guzel, 2011) el cdr2 codifica una homologación del $88 \%$ al mdr1, cumpliendo las mismas funciones de resistencia a los azoles. (La Foret, 2010)

Métodos de laboratorio que determinan la resistencia a los antifúngico

Con la presencia de las mutaciones puntuales de los microrganismo que estaban apareciendo y transformando a los hongos en agentes resistentes a la farmacología convencional conocida, se elaboraron métodos de laboratorio y se los estandarizo para la cuantificar y calificar 


\section{Cepas de Candida albicans en pacientes con diabetes mellitus}

Vol. 3, núm. 1., (2019)

Javier David Lara Icaza

a la resistencia de los antimicóticos y a su vez aprobados por la CLSI (Clinical And Laboratory

Standards Institute); estos métodos fueron: (Cantón, 2007)

- Métodos de microdilución para levaduras (descontinuados).

- Método de macrodilución para levaduras (descontinuados).

- Método por difusión simple (descontinuados).

- Método de etest (descontinuados).

- Método colorimétrico (actuales).

- Métodos cim (actuales).

Diabetes, factores intrínsecos y extrínsecos que colaboran con las candidiasis

Que es la diabetes mellitus

La diabetes mellitus es un grupo de enfermedades metabólicas caracterizadas por la hiperglicemia, consecuencia de defectos en la secreción y/o en la acción de la hormona insulina, secretada por el páncreas. La hiperglucemia crónica está obligada en largo plazo a dañar, y a causar disfunción e insuficiencia en diferentes órganos especialmente los ojos, riñones, nervios, corazón y vasos sanguíneos.

A qué se debe

Causada por la baja producción de la hormona insulina, secretada por las células $\beta$ de los islotes de langerhans del páncreas endocrino, que repercutirá en el metabolismo de los hidratos de carbono, lípidos y proteínas, (Yánez, 2009) el páncreas no fabrica la cantidad de insulina requerida por el cuerpo humano, la cual necesita para metabolizar los hidratos de carbono y no 


\section{Cepas de Candida albicans en pacientes con diabetes mellitus}

Vol. 3, núm. 1., (2019)

Javier David Lara Icaza

permitiendo el ingreso de la glucosa de la sangre a las células para su posterior conversión en energía.

Respuesta inmunológica frente a cándida spp

Las especies de cándida, particularmente cándida albicans, colonizan el tracto gastrointestinal, el aparato respiratorio, la vagina, el pene, la piel y las cavidades. La transición de la colonización a la infección depende de factores del huésped y del propio microorganismo. (Forbes, 2009)

Los principales componentes de la respuesta inmunológica frente a cándida spp. Son: inmunidad innata (neutrófilos, monocitos) con el reconocimiento de las levaduras, hifas y pseudohifas por una serie de receptores (tlr, betaglucanos) desencadenando una respuesta que lleva a la destrucción de los microorganismos por mecanismos oxidativos y no oxidativos. (Martin, 2010)

1) Activación del complemento por las vías clásica, alterna y de la lectina (gracias a la proteína MBL), facilitando la fagocitosis del microorganismo. (Martin, 2010)

2) Fagocitosis de las esporas por parte de células dendríticas que inducen a una respuesta celular th1; las pseudohifas desencadenan una respuesta de los linfocitos th2. Las células nk inducen la actividad anticandida en los fagocitos, mediante la síntesis de ifn- $\gamma$ (Martin, 2010)

Los factores predisponentes más importantes a la infección por candidas pp. Son: edades extremas de la vida, diabetes mellitus, carencias nutricionales, uso prolongado de antibióticos e 


\section{Cepas de Candida albicans en pacientes con diabetes mellitus}

Vol. 3, núm. 1., (2019)

Javier David Lara Icaza

inmunosupresión, sobre todo de tipo celular. La inmunidad celular es el mecanismo más importante para prevenir la candidiasis, en los pacientes con diabetes la aparición de la candidiasis correlaciona con cifras bajas de linfocitos t.

Los valores altos de la glicemia ocasionada por la diabetes mellitus, provocan que las infecciones tenga lugar, debido a la disminución de la fagocitosis relacionada por la hiperglicemia aún más si existe desnutrición, trastornos de la hidratación o del ph sanguíneo. El quimiotactismo y el poder microbicida de los linfocitos están muy disminuidos en los diabéticos. La opsonización no es del todo exitosa porque la glicemia trastorna los factores de la inflamación volviendo inestable a la cascada del complemento. La alteración en el organismo son colosales y las infecciones del tipo oportunistas se convierten en el mayor enemigo de los pacientes inmunodeprimidos.

Factores intrínsecos y extrínsecos que colaboran para la instauración de una micosis.

Para que una infección se instaure en el individuo, se debe contemplar ciertos factores, que pueden ser propios del huésped (intrínsecos) o externos del medio circundante (extrínsecos), los mismos que van a proporcionar una ventaja logarítmica creciente a los microorganismos que van a colonizar y presentar una infección.

\section{Factores intrínsecos}

Dentro de la economía humana hay factores o también llamado circunstancia desencadenante que desequilibran la homeostasia del organismo y lo llevan a estar vulnerables frente a un sin número de infinitas posibilidades de contraer una infección. Para ellos se determinó los factores intrínsecos que pueden afectar a un individuo. Los cuáles son: 


\section{Cepas de Candida albicans en pacientes con diabetes mellitus}

Vol. 3, núm. 1., (2019)

Javier David Lara Icaza

- La edad.

- El género.

- Sistema inmune

Factores extrínsecos

Hay factores externos que afectan indirectamente al organismo debilitándolo de forma progresiva y permitiendo que las infecciones micóticas se acentúen en los individuos. En la actualidad estos factores se fortalecen por el modo vida de la personas y de las debilidades económicas de la población, devolviéndose en condicionantes reales que promueven a múltiples padecimientos.

- Temperatura/clima.

- Condiciones higiénicas.

- Condición socio cultural.

- Condición anímica.

\section{Conclusiones.}

1. Los investigadores de estudio Sardi y colaboradores concluyeron que los resultados hallados de pacientes diabéticos tienen una cierta resistencia a los azoles, tal vez porque estos pacientes ya han tenido contacto con terapias antifúngicas con azoles y pueden ya no ser tan eficaz para los tratamiento de periodontales convencionales contra cándida. (Sardi, 2013)

2. El colombiano Gutiérrez y colaboradores, en el 2007, "determinaron la sensibilidad al 


\section{Cepas de Candida albicans en pacientes con diabetes mellitus}

Vol. 3, núm. 1., (2019)

Javier David Lara Icaza

fluconazol y al voriconazol de aislamientos de cándida spp. Obtenidos de la mucosa oral de 54 pacientes con sida hospitalizados"; de los cuales se comprobó que el 72,9\% de los aislamientos de cándida spp. Fueron sensibles al fluconazol; 6,3\%, sensibles dependientes de la dosis, y el 20,8\%, resistentes. A través del método colorimétrico. Cabe establecer que estos resultados se basan en una enfermedad degenerativa drástica que es el hiv; y no a una investigación directamente en pacientes diabéticos.

3. En Ecuador no hay una investigación publicada de este tipo, la más cercana fue en el 2003, patrocinada por los Laboratorios Pfizer en estados unidos, la cual promovió a la Dra. Catalina de Bedout y colaboradores que tomaran la iniciativa con países de la región como: Ecuador, Venezuela y Colombia (CELA) para una investigación: evaluación de la susceptibilidad de especies de cándida al fluconazol por el método de difusión de disco, las muestras fueron de pacientes atendidos en consulta externa o en salas de hospitalización de centros asistenciales en Colombia, Ecuador y Venezuela.

4. Se aisló 2.139 candidas spp. Siendo cándida albicans el microorganismo más frecuentemente aislado el $62 \%$ (1.326), y de mostrando que el $6.8 \%$ fue resistente al fluconazol, eso equivale a 144 pacientes. Los centros con el mayor número de C. Albicans resistentes al fluconazol fueron el hospital militar de Ecuador con $(7,2 \%)$ y el hospital universitario de Caracas, Venezuela, con (5,9\%). (Bedout, 2003)

5. La infecciones oportunistas por cándida albicans en pacientes diabéticos están ocasionando una tasa alta de incidencia en las infecciones candidiásica y por la cultura ecuatoriana a la automedicación estamos promoviendo, en ser uno de los países con el mayor grado de resistencia a los antifúngicos de la región. 


\section{Cepas de Candida albicans en pacientes con diabetes mellitus}

Vol. 3, núm. 1., (2019)

Javier David Lara Icaza

6. El clotrimazol reveló una sensibilidad del 59\% frente una resistencia del $3 \%$ y solo un $38 \%$ obtuvo una sensibilidad intermedia. El último antifúngico testado fue el fluconazol con el $32 \%$ de sensibilidad, una resistencia del $23 \%$ en comparación $45 \%$ de sensibilidad intermedia.

7. Estos fármacos evidencia que la sensibilidad estas disminuida. En lo que concierne a la resistencia, solo el fluconazol está alto, siendo este, el único que cumple con los rangos del 20 a 30\% contemplados en la hipótesis, pero se deja de entrever que la sensibilidad intermedia esta incrementada. En promedio entre los cuatro antifúngicos da $46.75 \%$ casi la mitad de todos los casos. Indicando que van en camino a convertirse en resistente, si no se toma medias a tiempo y se concientiza a la ciudadanía de la problemática que es la resistencia microbiana.

8. Entre las zonas corporales, a las cuales se ven expuesto, los pacientes diabéticos a sufrir de una infección por candidiasis, va a estar mediada por el buen control de la diabetes mellitus. Siendo esta una enfermedad de fondo, un factor intrínseco degenerativo, que no solo debilita al sistema inmune, si no que deshidrata y quebranta la piel, cambia el ph corporal, produce desnutrición por la mala asimilación de los nutrientes, produce estados inflamatorios en los órganos, obstaculiza la formación y el tránsito de las células inmunocompetentes, lo que permite a la cándida spp, como parte de la microflora, se transformarse en oportunista y causar una infección en el organismo.

Estas regiones, están los órganos de choque donde aparecer los signos o señales de las infecciones, de las cuales se tomaron los diferentes especímenes para el estudio micológico: el espacio interdigital de la mano, consiguió el $25 \%$ del total de las muestras; el espacio interdigital 


\section{Cepas de Candida albicans en pacientes con diabetes mellitus}

Vol. 3, núm. 1., (2019)

Javier David Lara Icaza

de los pies con el 5\%; el hisopado del glande con un 6\%; el hisopado vaginal con el 24\%; el intertrigo de la piel alcanzo el 4\%; la orina el 18\%; la piel un 8\%; el raspado del cuerpovungueal un 5\%; el raspado del lecho ungueal 2\% y por último el raspado del eponiquio con el $2 \%$ de las muestras. Y a esto se la relaciona con los factores extrínsecos como la temperatura húmeda propia de la región 80 c.

Se debe de vigilar el diagnóstico presuntivo de candidiasis si no estamos seguro del agente causal cándida albicans, para ello le correspondería enviar desde la primera consulta el cultivo para confirmar el agente productor de la infección. Para evaluar y brindar una mejor administración de los antimicóticos es importante solicitar que los pacientes diabéticos vengan acompañados con un familiar para concienciar y crear un compromiso desde la consulta con los pacientes y familiares sobre la importancia de culminar el tratamiento y sobre todo vigilar si el paciente está cumpliendo con las visitas periódicas al endocrinólogo con la intención que esté llevando una diabetes controlada.

Además es recomendable que se explique al paciente que, por su condición diabética debe de mantenerse la higiene siempre, recordando que la humedad favorece el crecimiento de los hongos, el estado de ánimo es fundamental ya que asistimos al sistema inmune, las endorfinas son adyuvantes de aumentar las defensas en condiciones óptima y a todo esto le agregamos una dieta balanceada, sin que la misma eleve el nivel de azúcar en la sangre podremos nutrir al organismo, evitando la instauración de microorganismos oportunistas. 


\section{Cepas de Candida albicans en pacientes con diabetes mellitus}

Vol. 3, núm. 1., (2019)

Javier David Lara Icaza

\section{Bibliografía.}

Alburquerque, C., et al. (2009). Distribución y susceptibilidad a fluconazol de levaduras del género cándida aisladas en pacientes hospitalizados y ambulatorios. Santiago.- chile. Revista chilena de infectología. Página 435.

Bedout, C., et al. (2010). Candida y candidiasis invasora: un reto continúo para su diagnóstico temprano. Bogotá.- Colombia. Revista de la asociación colombiana de infectología. Páginas 1-13.

Cantón, E., et al., (2007). Métodos estandarizados por el clsi para el estudio de la sensibilidad a los antifúngico (documentos m27-a3, m38-a y m44-a). Madrid.- España. Revista iberoamericana de micología y laboratorios Pfizer. Paginas. 1-24.

Cárdenas, C. (2008). Levaduras del género cándida de procedencia clínica. Evaluación de métodos de identificación. Barcelona.- España. Universidad de la laguna. Tesis doctoral. Páginas 43-65.

Carrillo A., et al. (2010). Antifúngico disponibles para el tratamiento de las micosis ungueales. Barcelona.- España. Revista iberoamericana de micología. Paginas. 49-56.

Cortés, a. Et al. (2011). Sensibilidad y especificidad entre dos medios cromogénicos para la identificación de cándida spp. México D:F-.México revista biomédica mexicana. Páginas 78-82.

Cowen, 1. Et al. (2012). Evolución de la resistencia antibiótica de cándida albicans. Buenos aires.- argentina. Evolution of drug resistance in cándida albicans. Resumen objetivo elaborado por el comité de redacción científica de siic. Laboratorios bago. Página. Http: // www .bago. Com/ bago arg/biblio /infecto 241web.htm.

Duarte, A., et al. (2011). Modalidades de la prueba del tubo germinal. Caracas.-Venezuela. Revista de la sociedad venezolana de microbiología. Páginas 66-68.

Forbes, B. (2009). Bailey \& Scott diagnóstico microbiológico. Buenos aires.- argentina doceava edición. Editorial médica panamericana. Páginas 26-42_696-712.

Gómez, C. (2010). Resistencia de levaduras del género cándida al fluconazol. Bogotá.Colombia. Revista colombiana de infectología. Publicado por scielo. Páginas 172-180.

Guery, B., et al. (2009). Gestión de la candidiasis invasiva y la candidemia en pacientes de la unidad de cuidados intensivos adultos no neutropénicos: parte i. Epidemiología y diagnóstico. Estados unidos. Revista on line. Intensive care med. Página 55-62.

Gutiérrez, M., et al. (2012). Estudio in vitro de antimicóticos contra cepas de cándida aisladas de pacientes del hospital general de México od. Ciudad de México DF.- México. Dermatología revista mexicana. Páginas 93-101. 


\section{Cepas de Candida albicans en pacientes con diabetes mellitus}

Vol. 3, núm. 1., (2019)

Javier David Lara Icaza

Gutiérrez C, et al. (2007). Sensibilidad a fluconazol y voriconazol de aislamientos de cándida spp., obtenidos de mucosa oral de pacientes con sida. Bogotá.- Colombia. Revista de infectología de Colombia. Páginas 183-189.

Guzel, A., et al. (2011). Evaluation of risk factors in patients with vulvovaginal candidiasis and the value of chromid candida agar versus chromagar candida forreco very and presumptive identification of vaginal yeast species. United state. Medical mycology. Páginas 16-25.

Ilarte, C. Et al. (2009). Pruebas para identificar especies de cándida en cavidad bucal. Caracas.Venezuela. Fundación acta odontológica venezolana. Volumen $47 \quad \mathrm{n}^{\mathbf{o}}$ 3.www.actaodontologica.com/ediciones/2009/3/art26.asp

Jaimez, A., et al. (2008). Portadores de cándida albicans en la mucosa oral: tipificación de 35 cepas con chromagar. México D.F...- México. Medicina interna de México. Páginas 265265.

La Forre, 1. (2010). Estudio de la pg. a 26, una proteína implicada en la arquitectura de la pared celular de cándida albicans. Valencia.- España. Universidad de Valencia. Páginas 9-15.

Lobaina, T., et al. (2010). Identificación de especies de cándida de importancia clínica con un método auxonograma modificado. La Habana.- Cuba. Revista cubana de medicina tropical. Versión on-line issn 1561- 3054.

Manzano P., et al. (2007). La resistencia a los antifúngico un problema emergente en México. México D.F.- México. Hospital de especialidades y universidad UNAM. Paginas. 23-26.

Manzano, P., et al. (2011). Levaduras causantes de onicomicosis en cuatro centros dermatológicos mexicanos y su sensibilidad antifúngica a compuestos azólicos. México DF.- México. Revista iberoamericana de micología. Páginas 32-35.

Martin, A., et al. (2010). Tratamiento de la infección fúngica basado en la respuesta inmunológica. Barcelona.- España. Asociación española de pediatría. Páginas 2-8.

Núñez, S., et al. (2011). Candidiasis. Guadalajara.- México. Hipócrates revista medicina. Página 12-15.

Paniagua, G., et a. (2010). Caracterización genotípica de cepas de cándida albicans aisladas de la mucosa oral y vaginal de pacientes no inmunocomprometidos. México D.F.- México. Revista médica Hospital German. Página 73.

Pappas, P., et al. (2009). Clinical practice guildelines for the management of candidiasis: update by the infectious diseases society of America. United States. Clinical infectious diseases. Página 503.

Pontón, j., et al. (2007). Diagnóstico precoz de las micosis por hongos levaduriformes. Madrid.España. Revista iberoamericana de micología. Página 181-186. 


\section{Cepas de Candida albicans en pacientes con diabetes mellitus}

Vol. 3, núm. 1., (2019)

Javier David Lara Icaza

Rodero, 1., et al. (2006). Método de difusión con discos para la determinación de sensibilidad a fluconazol en aislamientos de cándida spp. Buenos aires.- argentina. Revista argentina. Páginas 155-163.

Rueda, F. (2008). Caracterización de cepas de cándida albicans aisladas de la cavidad oral de pacientes portadores de hiv sanos. México D.F.- México. Publicado por universidad de colima.páginas28-31.

Sánchez, J., et al. (2009). Incidencia de cándida albicans en pacientes estudiadas en la ciudad de puebla. Puebla.- México. Acta cient estud. Página 7.

Sánchez, 1., et al. (2009). Infecciones micóticas superficiales. Lima.- Perú. Dermatología peruana. Páginas 258-264.

Tobar, E., et al. (2011). Candidiasis invasoras en el paciente crítico adulto. Santiago.- chile. Revista chilena de infectología. Publicación on line scielo. Páginas 41-49.

Torres, N., (2008). Métodos para la detención de la resistencia de los antimicóticos. Bogotá.Colombia. Revista de la asociación colombiana de infecciones. Publicación scielo on line.

Torres, N., et al. (2009). Evaluación mediante tres técnicas de susceptibilidad a fluconazol en especies de cándida aisladas en pacientes con infecciones invasoras Colombia. Santiago.chile. Revista. Chilena de infectología. Páginas 135 -143.

Tortora, J., et al. (2007). Introducción a la microbiología. Buenos aires. Argentina. Editorial médica panamericana. Página 802.

Washington, C., et al. (2008). Monema. Diagnóstico microbiológico. Buenos aires.- argentina. Sexta edición. Editorial médica panamericana. Páginas 1106-1109_ 1164-1174_11781180. 